\title{
CONTROL OF A SERIES DC MOTOR DRIVE USING AC/DC CONVERTER
}

\author{
A. M. Dabroom \\ Yanbu Industrial College, Yanbu Industrial City - Kingdom of Saudi Arabia \\ Fax : +96604 3946111, Tel. +96604392 0213, P.O.Box: 30436 \\ E-mail: dbroommohmed@yahoo.com
}

\begin{abstract}
The fly-back converter is used to obtain a constant output power switching converter, this paper introduce an approach for speed control of a series DC motor using an AC/ DC converter. This approach is based on the cascade combination of a diode bridge rectifier and fly-back converter. The converter can be operates as buck or buck-boost converter according to the state variable of controlled switch operation. The supply current is approximately sinusoidal with a high power factor. The output voltage and current is achieved with a ripple free. Modeling and simulation of the system are performed using the differential equations which describing the system behavior in different conditions. The motor performance characteristic in different state of operation is controlled by controlling the duty ratio of the MOSFET. The simulation results are a good agreement when compared with experimental results.

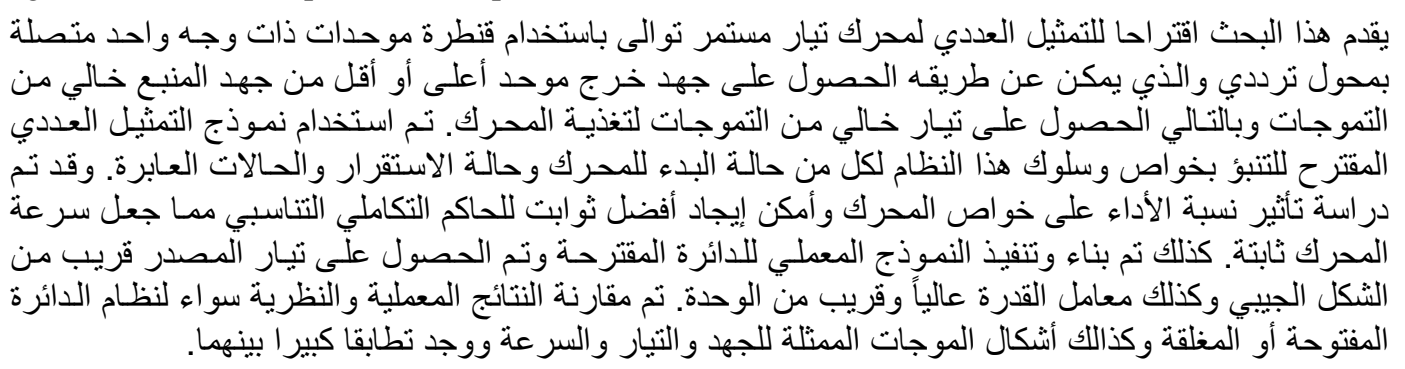

Keywords: Fly-back converter, buck-boost converter

\section{LIST OF SYMBOL}

B: Viscous friction coefficient

$\mathrm{C}$ :Filter capacitance

E: DC fly-back input voltage

fs : Switching frequency

im : Instantaneous motor current

is: Instantaneous supply current

i1 : Instantaneous inductor current

If: Motor field current

iDm : Diode current

$\mathrm{j}$ : Moment of inertia

Km: Back e.m.f. coefficient

Lm: Motor armature inductance

$\mathrm{Rm}$ : Motor armature resistance

TL: Load torque

Te: Motor developed torque

Vm: Motor input voltage

Vf: Motor field voltage

Vc: Capacitor voltage $\omega$ : Motor angular speed

$\omega r$ : Motor reference angular speed

D: Duty ratio of controlled switch

L1, R1: Inductance and resistance of the transformer primary

L2, R2: Inductance and resistance of the transformer secondary

\section{INTRODUCTION}

Power electronic converters can be classified into four different types on the basis of input and output voltage. Also, it can be classified on the basis of out put voltage as buck converter as $\mathrm{V}_{\mathrm{o}}=\mathrm{D}^{*} \mathrm{~V}_{\mathrm{i}}$

( $\mathrm{D}$ is the duty ratio of controlled switch; less than 1), boost converters $\mathrm{V}_{\mathrm{o}}=\mathrm{D}^{\prime} * \mathrm{~V}_{\mathrm{i}}$

( $\mathrm{D}^{\prime}$ is the duty ratio of controlled switch; more than 1)

Buck boost converters that has the desired step up and step down functions with

$\mathrm{V}_{\mathrm{o}}=-(\mathrm{D} / \mathrm{D}) \mathrm{V}_{\mathrm{i}}$; so it could use two cascaded converters using two controlled switches [1-2]. The fly-back converter is used to obtain a constant output 


\section{A. M. Dabroom, "Control of a Series DC Motor Drive Using AC/DC Converter"}

power switching converter. Also, it is used as a buck - boost converter using one MOSFET. The fly-back converter is the favorite choice among design engineers for low power application due to its low component count, cost-effective structure as well as its large dynamic range.[3-4].

Different schemes of fly back converters are used in power electronic applications. In [5-6], the buckboost converter type of active clamp is connected in parallel with the primary side of isolation transformer to recycle the energy stored in the leakage inductor of the transformer and to limit the peak voltage stress of the switching devices, but the efficiency of operation for this type is not high. Continuous current mode (CCM) fly back converter, offering a lower peak input current, and hence, lower conduction losses, than the constant current frequency, discontinuous mode

Discontinuous current mode (DCM) fly back converter [7-8]. Although the variable frequency fly back converter appears to be a simple circuit [9], the modeling of the circuit dynamics is not well understood, and consequently, control- loop compensation is often designed using a cut- and- try approach.

In recent years, advanced development of fly-back converters have attracted special in small machine rating drive applications. A variety of circuit topologies of fly-back converters using MOSFET's and IGBT's as well as static inductor and power transistor have some remarkable advantages such as, simple control scheme, quick response and high performance in steady state and transient state operations [10-11].

An AC/DC fly-back converter introduced in this paper, fed a dc series small motor is analyzed. Experimental and numerical simulation for this system are studied to obtain dynamic and steady state performance. A good agreement between theoretical and experimental results has been achieved.

\section{MODELING AND SYSTEM DESCRIPTION}

Figure [1], shows the schematic diagram of the $\mathrm{AC} /$ DC converter with the control system. This system consists of an AC/DC fly-back converter using one MOSFET and a series DC motor. To control the DC motor applied voltage, The DSP 1102 board is used to control duty ratio of the MOSFET operation.

During the operation, an AC/DC fly-back converter stores energy in its transformer winding from input rectified DC source, when the switch is on, then releases this stored energy into the outputs after the switch is turned off. In steady state operation the amount of energy stored and released per cycle has been adjusted, the output voltage can be regulated. By controlling the switch duty ratio. The gate pulses is given as follows duty ratio

$$
D=\frac{T_{\text {on }}}{T}
$$

Where, $T_{\text {on }}$ is the on period of the MOSFET $\left(M_{1}\right)$, and $\mathrm{T}$ is the total period. On time period $\mathrm{T}_{\text {on }}$ can be varied by changing the control voltage signal that is compared with the carrier signal to obtain the gate pulses.

The state of the controlled switch and the diode $\left(D_{m}\right)$, are defined as:

$$
\begin{aligned}
& A=\left[\begin{array}{ll}
1 & \text { when } \mathrm{M} \text { is on } \\
0 & \text { when } \mathrm{M} \text { is off }
\end{array}\right. \\
& P=\left[\begin{array}{ll}
1 & \text { when } \mathrm{D}_{\mathrm{m}} \text { is conducting } \\
0 & \text { when } \mathrm{D}_{\mathrm{m}} \text { is not conductin }
\end{array}\right.
\end{aligned}
$$

The variable $\mathrm{A}$ and $\mathrm{P}$ are standing for active and passive switches respectively, and are binary variables, i.e. they are restricted to the set $\{1,0\}$. An equation is derived for each state variable of the active switch and passive switch throughout a complete switching cycle. From steady state analysis the circuit operation can be divided in three modes of operations.

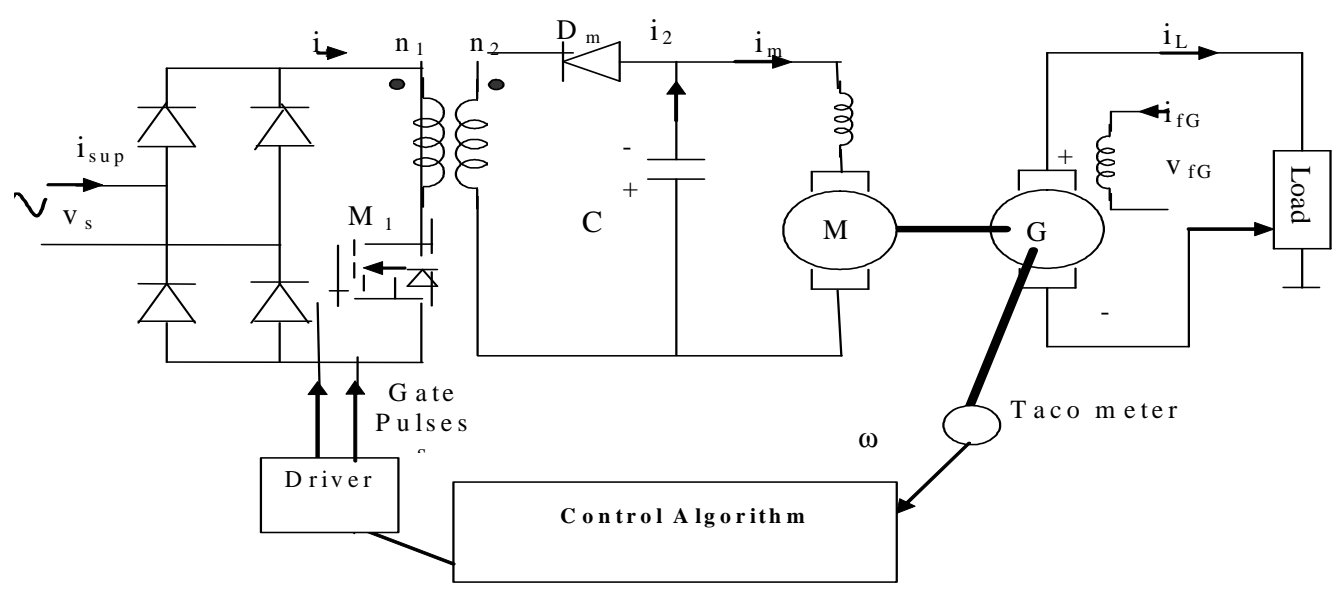

Fig. 1 Schematic diagram of fly-back converter 


\section{Mode 1:}

The equivalent circuit in this mode of operation is shown in fig. (2), the MOSFET is on and the energy transferred from the supply to the transformer. Also, the capacitor will discharge its energy in the dc motor winding, while diode $\mathrm{D}_{\mathrm{m}}$ is off.

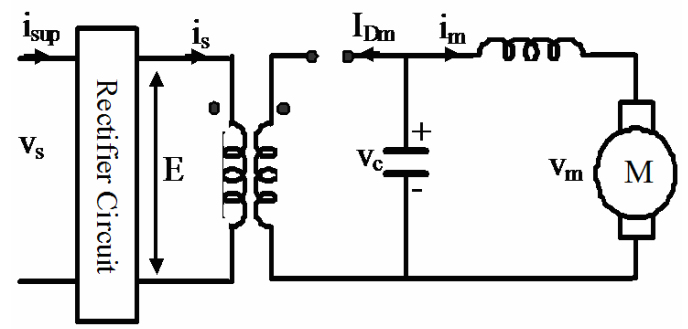

Fig. 2 Mode (1)

$$
\begin{aligned}
\frac{d i_{s}}{d t} & =\frac{1}{L_{1}}\left[-E-i_{s} \cdot R_{1}\right] \\
i_{D m} & =0.0 \\
\frac{d V_{m}}{d t} & =\frac{1}{c}\left[-i_{m}\right]
\end{aligned}
$$

and,

$$
\begin{aligned}
& \frac{d i_{m}}{d t}=\frac{1}{L_{m}}\left[V_{m}-i_{m} \cdot R_{m}-K_{m} \cdot \omega \cdot i_{m}\right] \\
& \frac{d \omega}{d t}=\frac{1}{J}\left[K_{m} \cdot i_{m}{ }^{2}-B \cdot \omega-T_{L}\right]
\end{aligned}
$$

Where,

$$
T_{e}=K_{m} \cdot i_{m}
$$

\section{Mode 2:}

The MOSFET is off and Dm is on to release the stored energy from the transformer to charge the capacitor via diode $\mathrm{Dm}$, The switches state are $(\mathrm{A}=0$, $\mathrm{P}=1$ ) as shown in Fig. 3, the supply current is:

$i_{s}=0.0$

The motor current will decay and still in the same direction to freewheel the stored energy in the motor winding.

$$
\frac{d i_{D m}}{d t}=\frac{1}{L_{2}}\left[-V_{m}-i_{D m} \cdot R_{2}\right]
$$

and the capacitor current is :

$\frac{d V_{m}}{d t}=\frac{1}{C}\left[i_{D M}-i_{m}\right]$

The motor running equations are:

$$
\begin{aligned}
& \frac{d i_{m}}{d t}=\frac{1}{L_{m}}\left[V_{m}-i_{m} \cdot R_{m}-K_{m} \cdot \omega . i_{m}\right] \\
& \frac{d \omega}{d t}=\frac{1}{J}\left[K_{m} \cdot i_{m}{ }^{2}-B \cdot \omega-T_{L}\right]
\end{aligned}
$$

Where,

$$
T_{e}=K_{m} \cdot i_{m}
$$

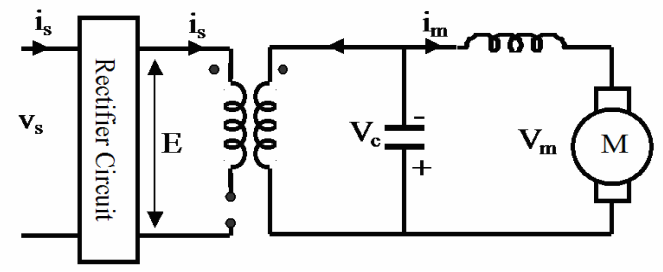

Fig. 3 Mode (2)

Mode 3:

The switches state variables are $(\mathrm{A}=0, \mathrm{P}=0)$, the MOSFET is off and diode $D_{m}$ is off, so the capacitor voltage reverse the diode so the capacitor discharge in the motor winding as shown in fig. (4), and

$$
\begin{aligned}
& i_{s}=0.0 \\
& i_{D m}=0.0
\end{aligned}
$$

The DC motor equations are:

$$
\begin{aligned}
& \frac{d V_{m}}{d t}=\frac{1}{C}\left[-i_{m}\right] \\
& \frac{d i_{m}}{d t}=\frac{1}{L_{m}}\left[V_{m}-i_{m} \cdot R_{m}-K_{m} \cdot \omega \cdot i_{m}\right] \\
& \frac{d \omega}{d t}=\frac{1}{J}\left[K_{m} \cdot i_{m}{ }^{2}-B \cdot \omega-T_{L}\right]
\end{aligned}
$$

Where,

$$
T_{e}=K_{m} \cdot i_{m}
$$

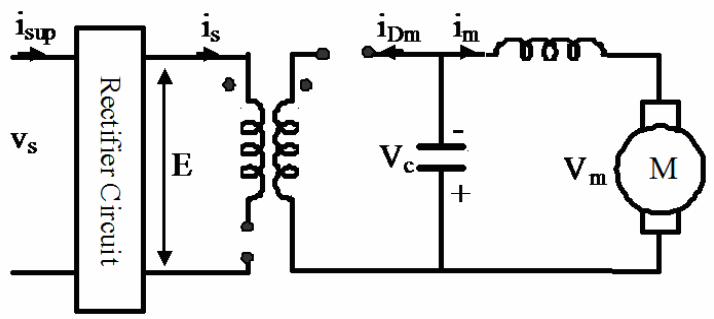

Fig. 4 Mode (3)

\section{MODELING OF THE DRIVE CIRCUIT}

Control pluses can be represented by the following equation [8] as the timing voltage:

$$
V a=M_{A}[1-X / T]
$$

Where $\mathrm{Va}$ is the carrier voltage, $\mathrm{M}_{\mathrm{A}}$ is the maximum voltage $(5 \mathrm{v}), \mathrm{X}$ is the time instant which is changed from zero to $\pi$ in radians and $T$ is the chopping period in radians which is given by

$$
T=\frac{1}{f_{s}}
$$

The gate pluses have values of $5 \mathrm{v}$ or zero. It has a value of $5 \mathrm{v}$ when the control voltage is greater than the timing voltage, and it has a zero volt when the control voltage less than the timing voltage. 


\section{A. M. Dabroom, "Control of a Series DC Motor Drive Using AC/DC Converter"}

\section{SIMULATION AND EXPERIMENTAL RESULTS}

The experimental system is built in the laboratory as a prototype. Figure 5, shows the steady-state characteristics for motor speed versus duty ratio at 0.25 Full load.

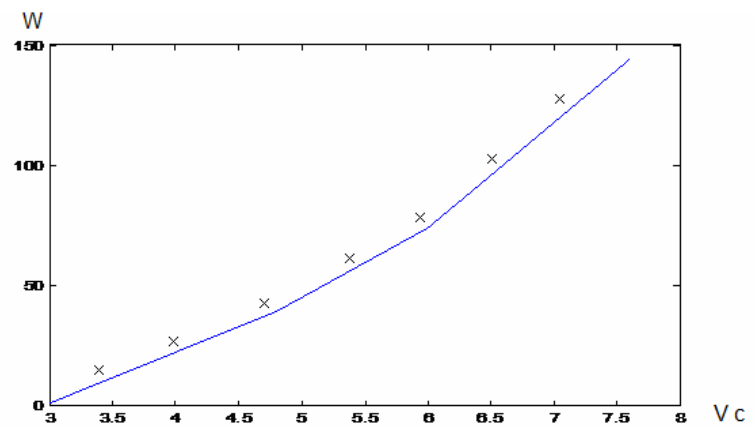

Fig. 5 simulation and experimental results for motor speed versus control voltage

The steady-state waveforms of the supply voltage, current, motor voltage, motor current and in the open loop operation with duty ratio $50 \%$ and 0.25 full load are shown in Fig. 6.

\section{Run-up behavior and transient conditions}

Fig. (7), shows the simulation and experimental waveforms at duty ratio $50 \%$ and 0.25 full load for Run-Up behavior. It is noticed that the supply current is increased at run-up.

The transient operation condition of the system is shown in fig. (8), the transient simulation and experimental results are obtained for $20 \%$ positive and negative step change in load from the exsisting load with $50 \%$ duty ratio. It is observes that the speed is decreased with increasing the load and the speed is increasing with decreasing the load.

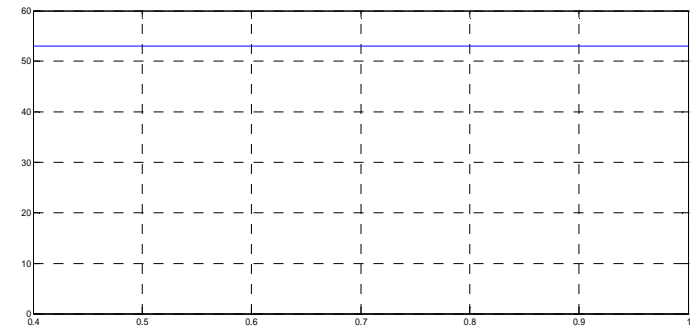

Simulation

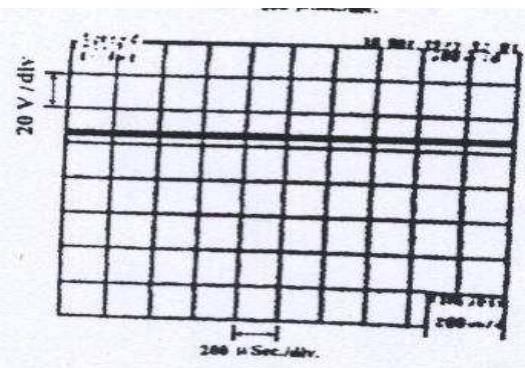

Experimental

(a) motor voltage

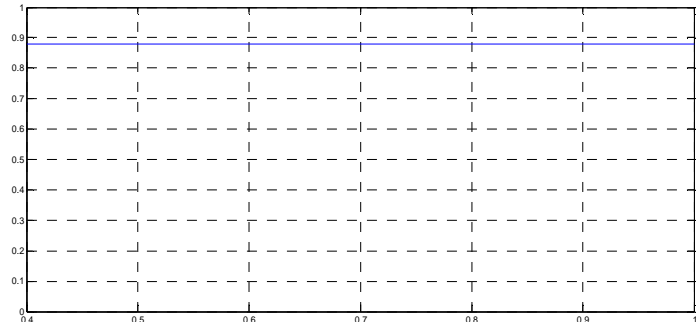

Simulation

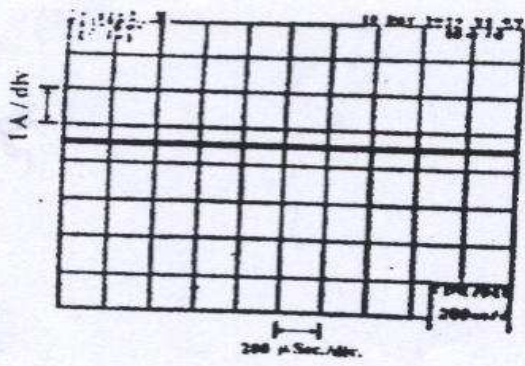

Experimental

(b) Motor current
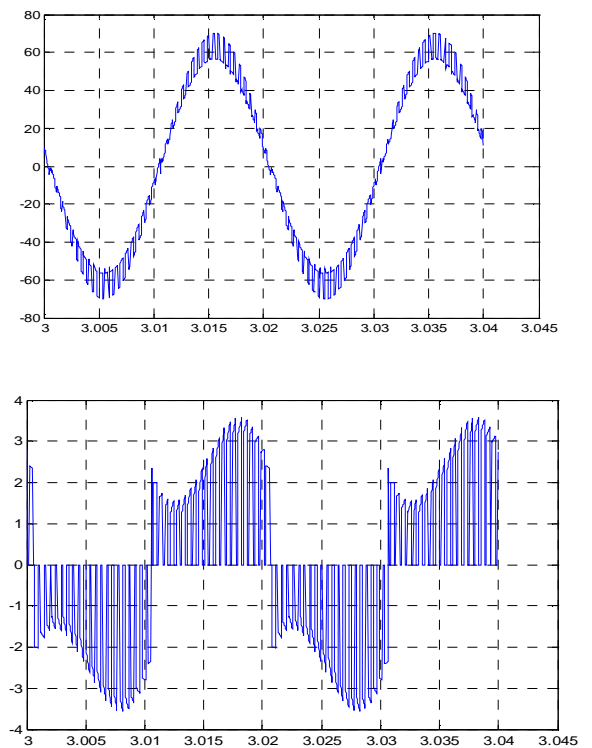

Simulation

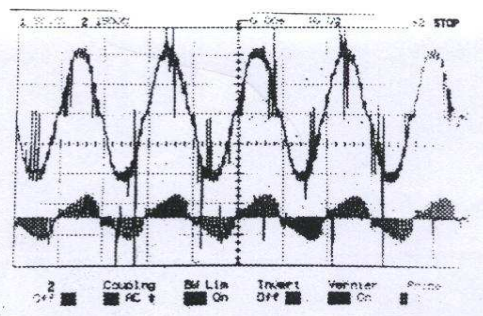

Experimental

(c) supply voltage and current

Fig. 6 Steady - state simulation and experimental results at duty ratio $50 \%$ and 0.25 full load 


\section{A. M. Dabroom, "Control of a Series DC Motor Drive Using AC/DC Converter"}
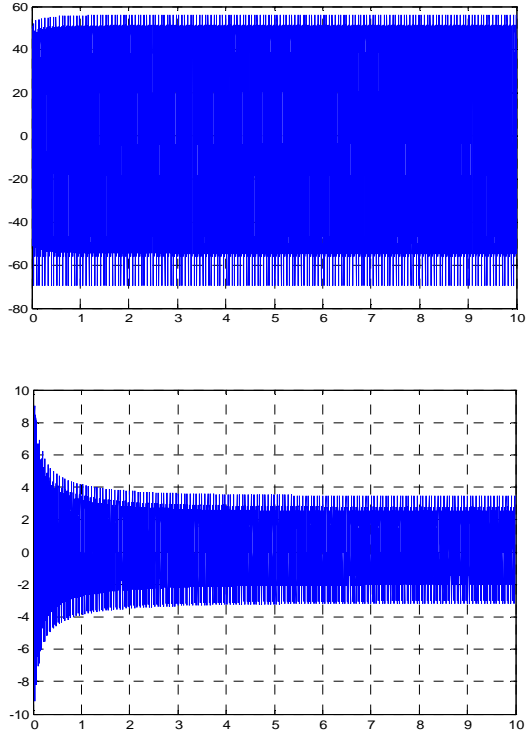

Simulation

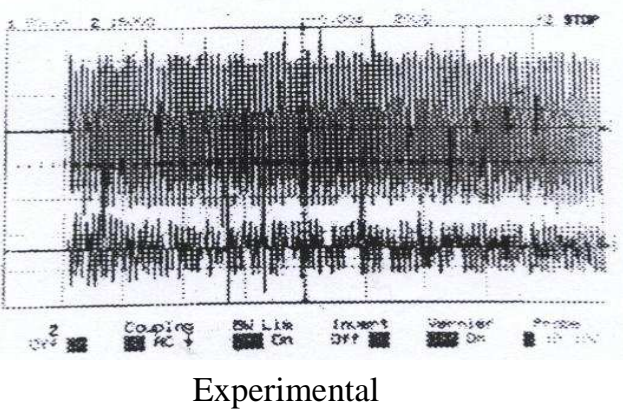

(a) supply voltage and current

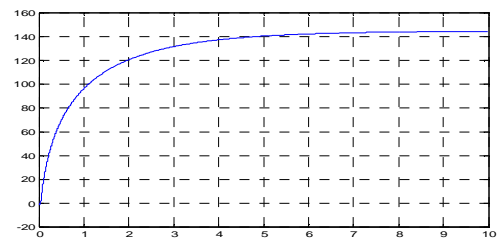

Simulation

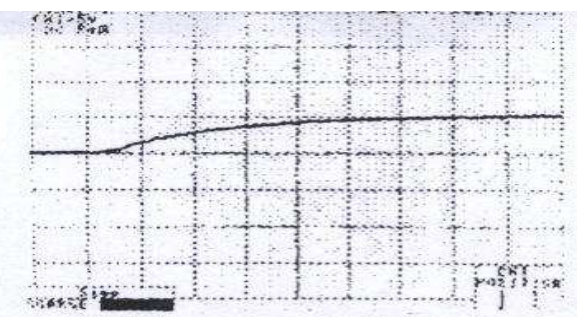

Experimental

(b) Motor speed

Fig. 7 Run-Up simulation and experimental results at duty ratio $50 \%$ and 0.25 full load

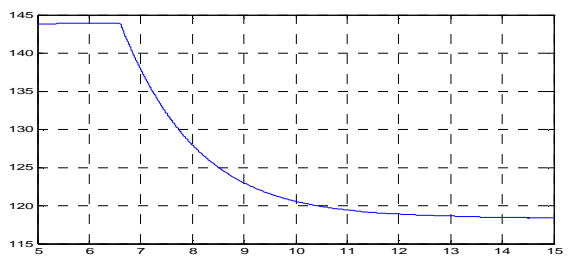

Simulation

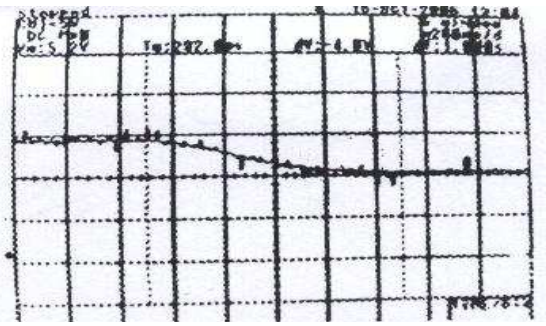

Experimental

(a) Step in load positive

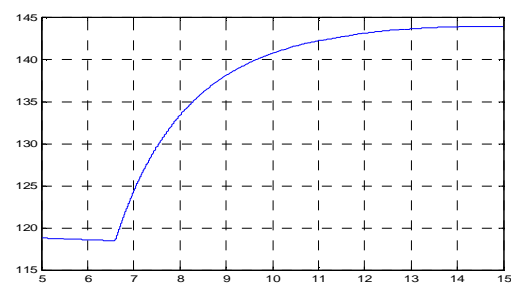

Simulation

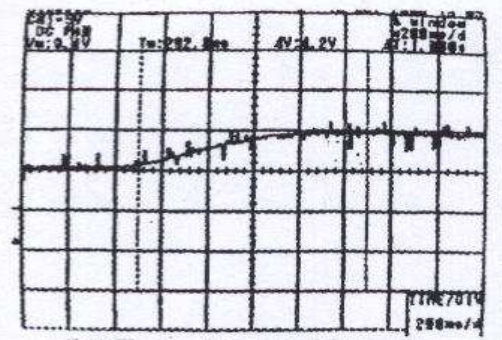

Experimental

(b) Step in load negative

Fig. 8 simulation and experimental results for $20 \%$ positive and negative step change in load with duty ratio $50 \%$

\section{CONCLUSION}

The modeling and simulation of the Fly back converter are presented for open loop speed control system. The DC motor applied voltage can be achieved by controlling the controlled switch duty ratio. The result shows that supply current is approximately sinusoidal with almost unity power factor. The output voltage and current are reasonably ripple free. The best responses for load change can be obtained. The transient conditions are selected for operation when the load changes within $\pm 20 \%$ from existing load. The comparison between simulation and experimental results are proved good agreement with each other. 


\section{A. M. Dabroom, "Control of a Series DC Motor Drive Using AC/DC Converter"}

\section{APPENDIX}

\section{The motor parameters:}

The test motor is a separately excited dc motor, 220 volt, $0.5 \mathrm{HP}, 1.9$ amp, 3000 r.p.m

It has the following measured parameters:

$\mathrm{R}_{\mathrm{m}}=10.5 \Omega, \quad \mathrm{L}_{\mathrm{m}}=0.11783 \mathrm{H}, \quad \mathrm{R}_{\mathrm{F}}=550 \Omega$,

$\mathrm{B}=0.0001 \mathrm{Nm} /(\mathrm{rad} / \mathrm{sec}), \mathrm{K}_{\mathrm{m}}=0.345$ Volt $/$ $(\mathrm{rad} / \mathrm{sec}) \mathrm{J}=0.0015 \mathrm{Km} . \mathrm{m}^{2}$.

The fly-back converter parameters:

The parameters of the designed system are:

$$
\begin{array}{ll}
\mathrm{L}_{1}=\mathrm{L}_{2}=0.478 \mathrm{H}, & \mathrm{R}_{1}=\mathrm{R}_{2}=2 \mathrm{\prime} \Omega, \\
\mathrm{C}=2200 \mu \mathrm{f}, & \mathrm{Fs}=2200 \mathrm{~Hz}
\end{array}
$$

\section{REFERENCES}

[1] Ray Ridley, " Fly back converter with no sunbbers", Power System Design Europe , pp. 16-18. , November 2007

[2] Ray Ridley, "Analyzing the Sepic converters ", Power System Design -Europe , pp. 14-19. , November 2006

[3] Chuanwen Ji, K. Mark Smith and Keyue M. Smedly, "Cross Regulation in Fly Back Converters Solution”, IECON' 99, Achen , germany sept. 1999,

[4] M. Rukonuzzaman, Mamun Abdullh Al, Shinji Sato, and Moisseev Serguei, "Soft Commutated Power Converter With High Frequency Transformer Secondary Side Control Scheme", EPE-PEMC2002, Dubrovnik \& Cavtat, crowatia, PP. 1-10. , Sept. 2002
[5] Billy K. H. Wong, and Henry Shu-hung Chung. "A systematic Graphing Technique for SmallSignal Low- Frequency Characterization of PWM DC/DC Converters", IEEE trans. On Industrial Elect, Vol. 47, No. 1, PP 45-53. , Feb. 2000.

[6] B. P. Divakar and Danny Sutanto, "Optimum Buck Converter With A Single Switch", IEEE trans. On Power Electronic, Vol. 14, No. 4, PP 636-642. , July. 1999.

[7]Bor- Ren Lin, Fang- Yu Hsieh, " Soft- switching Zeta- fly back converter with a buck- boost type of Active Clamp, ", IEEE Trans. On Industrial Electronic, Vol. 54, No. 5, PP 2813-2822., Oct. 2007

[8] N.P. Papannikolaou, E.C.Tatakis, "Active voltage clamp in flyback converters operating in CCM mode under wide load variation, " IEEE Tans. On industrial Electronics, Vol. 51, No. 3, pp. 632640, June 2004.

[9] Bhim Singh and mahima Agrawal, " Analysis and design of single- phase power factor corrected AC- DC Cuk converter with high- frequency isolation", Int. Journal Energy Technology and policy vol.4,No 1/2, pp 161-171, 2006

[10] J. H. Chen, K. T. Chau, and C. C. Chan, "Analysis of Chaos in Current- ModeControlled DC Drive Systems", IEEE trans. On Industrial Elect, Vol. 47, No. 1, PP 45-53. Feb. 2000.

[11] B. Baha, " Modelling of Resonant SwitchedMode Converters Using Simulink", IEE Proc. Elect. Power system appl, Vol.145, No. 3, PP 159- 163, May 1998. 